\title{
Population divergence in plasticity of the AVT system and its association with aggressive behaviors in a Death Valley pupfish
}

\author{
Sean C. Lema
}

\begin{abstract}
Behavioral differences can evolve rapidly in allopatry, but little is known about the neural bases of such changes. Allopatric populations of Amargosa pupfish (Cyprinodon nevadensis) vary in aggression and courtship behaviors in the wild. Two of these wild populations were recently found to differ in brain expression of arginine vasotocin (AVT) - a peptide hormone shown previously to modulate aggression in pupfish. These populations have been isolated for less than 4000 years, so it remained unclear whether the differences in behavior and neural AVT phenotype were evolved changes or plastic responses to ecologically dissimilar habitats. Here, I tested whether these population differences have a genetic basis by examining how aggressive behavior and neural AVT phenotype responded to ecologically relevant variation in salinity ( 0.4 ppt or 3 ppt) and temperature (stable or daily fluctuating). Pupfish from Big Spring were more aggressive than pupfish from the Amargosa River when bred and reared under common laboratory conditions. Morphometric analysis of preoptic AVT immunoreactivity showed that the populations differed in how the AVT system responded to salinity and temperature conditions, and revealed that this plasticity differed between parvocellular and magnocellular AVT neuron groups. Both populations also showed relationships between neural AVT phenotype and aggression in the rearing environment, although populations differed in how aggression related to variation in magnocellular AVT neuron size. Together, these results demonstrate that the pupfish populations have diverged in how physical and social conditions affect the AVT system, and provide evidence that the AVT system can evolve quickly to ecologically dissimilar environments.
\end{abstract}

Keywords: Phenotypic plasticity; Aggression; Social behavior; Vasotocin; Vasopressin; Development; Evolutionary endocrinology; Osmoregulation; Evolution; Fish

\section{Introduction}

Hormonal and neural mechanisms that underlie behavior can be particularly sensitive to environmental conditions (Francis et al., 1993; Gilmour et al., 2005), yet the plasticity of these proximate pathways has rarely been considered in studies of adaptive evolution. While studies have examined the role of phenotypic plasticity in generating population variation in morphological and life history traits in the wild (Doughty and Reznick, 2004), considerably less is known about how plasticity contributes to variation in behavior (Carroll and Corneli, 1999). Studies of geographic variation in hormonal and neural phenotypes are needed to inform how behaviors evolve (Foster, 1999) and determine what role environmentally induced plasticity plays in the divergence process (West-Eberhard, 2005).

Pupfish in the Death Valley region of California and Nevada, USA, comprise a clade of remote populations that became isolated from each other less than 20,000 years ago (Miller, 1950). These populations occupy ecologically varied habitats that include freshwater springs, variable desert streams, and saline marshes (Soltz and Naiman, 1978). This environmental variation has generated differences among the populations in social behaviors including aggression and courtship (KodricBrown, 1981; Soltz and Hirshfield, 1981). The recent isolation of Death Valley pupfish in such diverse and variable habitats makes them an exceptional evolutionary system for studying the role that plasticity in neural and hormonal pathways plays during initial divergence of behavior between populations. 
Recently, Lema and Nevitt (2004a) found that two allopatric populations of Amargosa pupfish (Cyprinodon nevadensis) from the Death Valley region differed in expression of the peptide hormone arginine vasotocin (AVT) in the preoptic area of the hypothalamus. AVT and its mammalian counterpart - vasopressin - mediate a suite of processes including osmoregulation, stress responses, and sociosexual behaviors in vertebrates (Insel and Young, 2000; Goodson and Bass, 2001; Warne, 2002; Keverne and Curley, 2004). In teleost fish, AVT regulates hydromineral balance by altering ion and water transfer in gill and kidney tissues (Warne, 2002; Warne et al., 2002). Experiments with exogenous AVT have also established that this hormone mediates aggressive and reproductive behaviors in a variety of fishes including pupfish (Semsar et al., 2001; Lema and Nevitt, 2004b; Thompson and Walton, 2004). Corresponding to these functional roles, the production and secretion of AVT from the preoptic area respond to physiologically relevant changes in environmental conditions (Nürnberger et al., 1996; Hyodo et al., 2004).

Given the environmental responsiveness of the AVT system, it remained unclear whether the variation in preoptic vasotocin expression found between wild pupfish populations represents a genetically fixed difference or a plastic response of the AVT system to ecologically dissimilar habitats (Lema and Nevitt, 2004a). One of these populations occupies a habitat - Big Spring - that remains at a stable salinity $(0.4 \mathrm{ppt})$ and temperature $\left(\sim 27.5{ }^{\circ} \mathrm{C}\right)$ throughout the year. In contrast, conditions in the other population's habitat the Amargosa River - vary widely (Soltz and Naiman, 1978). The river is dominated by alternating desiccation and flooding. Temperatures in the river can shift rapidly more than $25{ }^{\circ} \mathrm{C}$ between day and night, and salinity varies between at least 0.2 and $3 \mathrm{ppt}$, although these salinity changes tend to occur gradually over seasons (Lema and Nevitt, 2004a).

Here, I examined the conditionality of aggressive behaviors and neural AVT phenotype in pupfish from the Big Spring and Amargosa River populations to determine the relative contributions of genetic and environmental influences to variation in expression of these traits (i.e., norms of reaction, Carroll and Corneli, 1999). I collected adult pupfish from the wild Amargosa River and Big Spring populations, spawned these adults in captivity, and reared the offspring under ecologically relevant conditions of salinity ( 0.4 ppt or $3 \mathrm{ppt}$ ) and temperature (stable or daily fluctuating). First, I examined whether the frequency of aggressive behaviors differed between populations or was affected by salinity or temperature conditions. Next, I used immunocytochemistry to localize and characterize AVT expression in the preoptic area of male fish, and then compared the norms of reaction for neural AVT phenotype to determine whether population origin, salinity, or temperature influenced the AVT system. Finally, I tested whether neural AVT phenotype in males from these populations showed any relationship with the level of aggression in the rearing environment.

\section{Materials and methods}

Study populations

Amargosa pupfish (C. nevadensis) adults were collected by minnow trap on 6 and 7 April 2001 from two allopatric populations - the Amargosa River and Big Spring. Both habitats are located in the Amargosa River drainage of the Death Valley region (Soltz and Naiman, 1978). Amargosa River pupfish (amargosae subsp.) were studied from a 10-12 km reach of the Amargosa River in Tecopa Canyon, San Bernardino County, CA, USA. Ash Meadows pupfish (mionectes subsp.) were collected from Big Spring in Nye County, Nevada, USA. The Death Valley region experienced a period of elevated precipitation and lake formation 3000 to 4000 years ago (Enzel and Wells, 1997), and these pupfish populations are thought to have been isolated for less than that time (Soltz and Hirshfield, 1981). Fish were transported to the Center for Aquaculture and Aquatic Biology of the University of California, Davis, where they were maintained in $1.2 \mathrm{~m}$ diameter, flow-through tanks at $26-28{ }^{\circ} \mathrm{C}$ and 0.4 ppt salinity under ambient photoperiod. All procedures were approved by the Animal Care and Use Committee (Protocol \#11191) of the University of California, Davis.

\section{Pupfish breeding}

Between 20 December 2003 and 10 March 2004, pupfish from the Amargosa River and Big Spring populations were spawned separately in groups of 6 females and 3 males in $114 \mathrm{~L}$ tanks $(90 \mathrm{~cm}$ long $\times 45 \mathrm{~cm}$ wide $\times 30 \mathrm{~cm}$ high). Given the protected conservation status of pupfish populations in Death Valley, 40 individuals (27 females and 13 males) from each population were used for breeding. Each female pupfish was thus used in $4-5$ breeding groups, and each male was used in 2-3 groups. A total of 14 groups were spawned for the Big Spring population, and 12 groups were spawned for the Amargosa River population.

Breeding tanks were maintained at $29.10 \pm 0.30^{\circ} \mathrm{C}$ (mean $\pm \mathrm{SE}$ ) and $0.4 \mathrm{ppt}$ salinity. Adult pupfish were spawned under a 14L:10D photoperiod, and the offspring were reared under this same photoperiod throughout the experiment. The bottom of each breeding tank was covered with cheesecloth; pupfish spawned on the cheesecloth which was then removed and placed into an aerated $2 \mathrm{~L}$ beaker. A single drop of acriflavine (Novalek, Inc., Hayward, California, USA) was added to each beaker to prevent fungal growth. Beakers were then maintained together in a water bath at $31.28 \pm 0.52^{\circ} \mathrm{C}$ until hatching (up to 8 days).

On the day of hatching, larval pupfish from each spawning group were transferred to $2 \mathrm{~L}$, aerated buckets $\left(32.06 \pm 0.75^{\circ} \mathrm{C} ; 0.4 \mathrm{ppt}\right)$ and fed a diet of Liquifry No. 1 (Interpet, Ltd., Darking, Surrey, England) and live brine shrimp nauplii (San Francisco Bay Brand, Inc., CA, USA). Within 4 days of hatching, larval pupfish were changed to a 1:1 mixture of spirulina and brine shrimp flake foods (Aquatic EcoSystems, Inc., Apopka, FL, USA) which they were fed through termination of the experiment.

\section{Salinity and temperature treatments}

Experimental treatments consisted of stable or daily fluctuating temperature regimes combined with $0.4 \mathrm{ppt}$ or $3.0 \mathrm{ppt}$ salinities. The experiment was thus a $2 \times 2 \times 2$ factorial design with population origin (Big Spring or the Amargosa River), temperature regime, and salinity as factors (Fig. 1). Groups of pupfish from the two populations were each reared under all combinations of temperature and salinity conditions. These temperature and salinity conditions were intentionally selected to represent the differences seen between the two Death Valley habitats. Big Spring is a stable environment with a temperature of $\sim 27.5^{\circ} \mathrm{C}$ and a salinity of 0.4 ppt year-round (Soltz and Naiman, 1978; Lema and Nevitt, 2004a). The Amargosa River can fluctuate more than $25^{\circ} \mathrm{C}$ between day and night, and can reach a salinity of at least 3 ppt (Lema and Nevitt, 2004a).

At 15 days after they were spawned and fertilized as eggs, larval pupfish were assigned to $2 \mathrm{~L}$ experimental rearing buckets. Since sexes cannot be distinguished in larval pupfish, four larvae were arbitrarily selected and placed into each rearing bucket. Subsequent analysis of the number of males per bucket at termination of the experiment showed no difference in sex ratio among treatments (one-factor ANOVA, $F_{7,64}=1.2209 ; P=0.3045$ ). All rearing buckets were maintained together in incubation tanks (114 L) with 10 buckets per tank. Initial sample sizes were $n=14$ rearing buckets for each temperature-salinity 


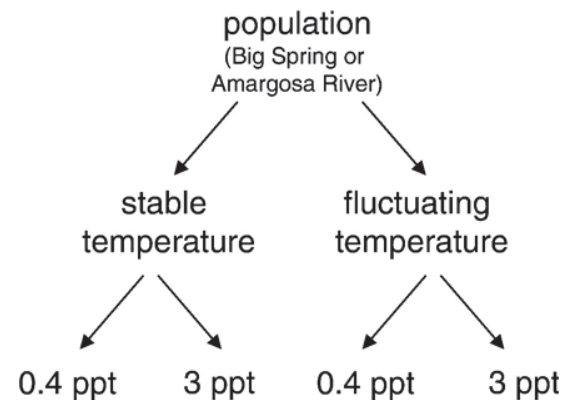

Fig. 1. Illustration of the experimental design. Captively bred pupfish from the Big Spring and Amargosa River populations were reared under combinations of stable or daily fluctuating temperatures, and $0.4 \mathrm{ppt}$ or $3 \mathrm{ppt}$ salinities.

treatment combination with Big Spring fish, and $n=12$ for all treatments with Amargosa River fish. Due to mortality, however, final sample sizes were smaller; the final sample sizes for behavior and AVT measures for each treatment are provided in Table 1.

Well water supplied directly to the Center for Aquatic Biology and Aquaculture facility was $0.4 \mathrm{ppt}$, so Instant Ocean $^{\circledR}$ (Aquarium Systems, Sarrebourg, France) was added to water in $190 \mathrm{~L}$ buckets to elevate salinity for the 3 ppt treatments (measured with a YSI meter, model 85, YSI Incorporated, Yellow Springs, OH, USA). Water for all treatments was heated in $190 \mathrm{~L}$ buckets prior to addition to treatment tanks; small amounts of water were added daily to treatment tanks to replace water lost to evaporation. Water temperatures in the stable and fluctuating temperature treatments were maintained by regulating the temperature in the $114 \mathrm{~L}$ incubation tanks with submersible aquarium heaters ( $300 \mathrm{~W}$; Aquatic Gardens). These heaters were on constantly in the stable temperature treatment tanks. Power to the heaters in the fluctuating temperature treatment tanks, however, was connected to the circuit that turned off the lights at the end of the $14 \mathrm{~h}$ photoperiod each day. This resulted in a rapid drop in water temperature each night until the lights came back on in the morning ( $10 \mathrm{~h}$ later). Water temperature was recorded in the incubation tanks at $30 \mathrm{~min}$ intervals using submerged temperature loggers (Hobo ${ }^{\circledR}$ Temp, Onset Computer Corp., Bourne, MA, USA). Analysis of these measurements over the $\sim 6$ month duration of the experiment showed that stable temperature treatment had a mean temperature of $27.90 \pm 0.004{ }^{\circ} \mathrm{C}$ (mean $\pm \mathrm{SE}$ ). The variable temperature treatment fluctuated $\sim 10^{\circ} \mathrm{C}$ daily between day and night $\left(28.92 \pm 0.04{ }^{\circ} \mathrm{C}\right.$; range, $\sim 21$ to $\left.33^{\circ} \mathrm{C}\right)$. The difference between temperature treatments is shown in Fig. 2.

\section{Quantification of aggressive behaviors}

When pupfish were 8-9 weeks of age, the frequency of aggressive charges and nips (combined) was determined for the group of pupfish in each
A

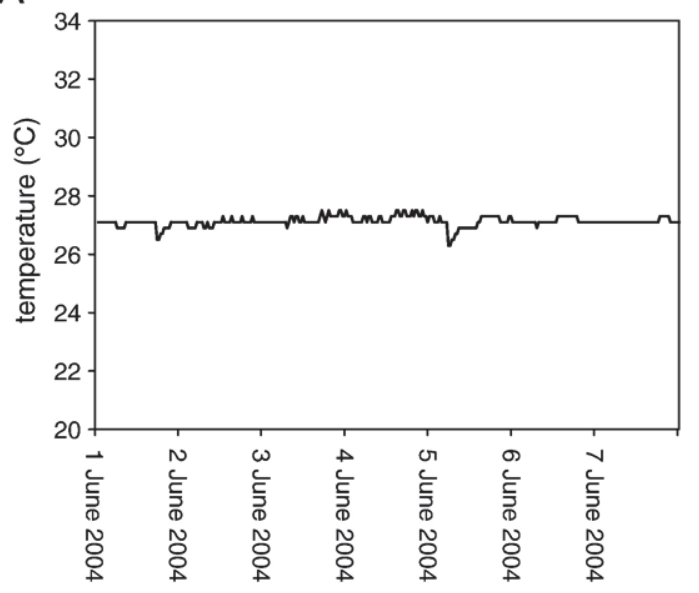

B

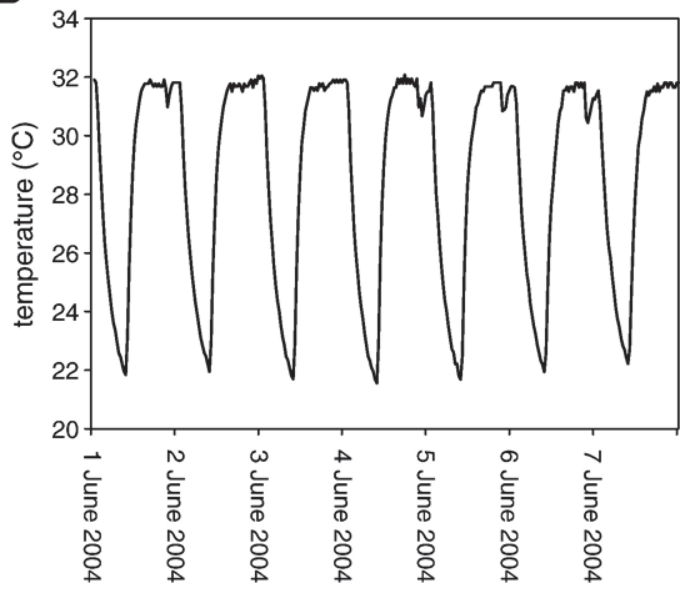

Fig. 2. Representative mean temperature profiles of the (A) stable and (B) daily fluctuating treatments from 1 week of the experiment (1 June 2004 to 7 June 2004).

experimental $2 \mathrm{~L}$ rearing bucket. Descriptions of these aggressive behaviors are provided in Lema and Nevitt (2004b). Given the small size of pupfish at this age, individuals were not marked. Behavioral values therefore represent the frequency of aggressive behaviors among the four fish in each rearing bucket. Aggressive behaviors were only assessed in rearing buckets that had four fish;

Table 1

Sample sizes and mean $( \pm \mathrm{SE})$ values for aggressive behavior and neural AVT phenotype by treatment

\begin{tabular}{|c|c|c|c|c|c|c|c|c|}
\hline \multirow{3}{*}{$\begin{array}{l}\text { Salinity } \\
\text { (ppt) }\end{array}$} & \multirow[t]{3}{*}{ Temperature } & \multicolumn{2}{|c|}{ Aggression test } & \multicolumn{5}{|c|}{ AVT immunoreactivity } \\
\hline & & \multirow[t]{2}{*}{$n$} & \multirow{2}{*}{$\begin{array}{l}\text { Charges } \\
\text { and nips } \\
\text { (per min) }\end{array}$} & \multirow[t]{2}{*}{$n$} & \multicolumn{2}{|c|}{ Parvocellular neurons } & \multicolumn{2}{|c|}{ Magnocellular neurons } \\
\hline & & & & & $\#$ & Size $\left(\mu \mathrm{m}^{2}\right)$ & $\#$ & Size $\left(\mu \mathrm{m}^{2}\right)$ \\
\hline \multicolumn{9}{|c|}{ Big Spring } \\
\hline 0.4 & Stable & 14 & $6.1 \pm 0.4$ & 6 & $82.00 \pm 5.70$ & $51.79 \pm 2.36$ & $51.17 \pm 4.00$ & $114.41 \pm 7.75$ \\
\hline 0.4 & Fluctuating & 12 & $7.4 \pm 0.6$ & 9 & $81.56 \pm 9.35$ & $46.54 \pm 1.15$ & $55.67 \pm 7.39$ & $127.62 \pm 9.82$ \\
\hline 3 & Stable & 14 & $6.3 \pm 0.4$ & 14 & $84.50 \pm 5.40$ & $55.88 \pm 2.35$ & $43.36 \pm 3.26$ & $124.40 \pm 5.65$ \\
\hline \multicolumn{9}{|c|}{ Amargosa River } \\
\hline 0.4 & Stable & 10 & $4.9 \pm 0.6$ & 6 & $105.00 \pm 4.58$ & $49.07 \pm 3.41$ & $53.67 \pm 5.48$ & $119.53 \pm 13.90$ \\
\hline 0.4 & Fluctuating & 10 & $5.9 \pm 0.3$ & 6 & $102.33 \pm 8.44$ & $49.37 \pm 1.06$ & $50.00 \pm 5.05$ & $125.95 \pm 13.39$ \\
\hline 3 & Stable & 11 & $5.8 \pm 0.4$ & 9 & $89.11 \pm 7.66$ & $50.05 \pm 1.79$ & $48.67 \pm 5.78$ & $122.67 \pm 9.94$ \\
\hline 3 & Fluctuating & 12 & $6.4 \pm 0.4$ & 12 & $95.67 \pm 6.43$ & $50.75 \pm 1.84$ & $46.25 \pm 5.93$ & $118.09 \pm 8.34$ \\
\hline
\end{tabular}


buckets where there had been mortality were not used. Sample sizes for these behavioral observations were $n=10-14$ replicate buckets per treatment (Table 1).

Two at a time, rearing buckets were moved from their incubation tanks into a 37.85 L tank for behavioral assessment. This tank was maintained at $28.70 \pm 0.03{ }^{\circ} \mathrm{C}$ (mean $\pm \mathrm{SE}$ ) (no difference among treatments, one-factor ANOVA, $\left.F_{7,87}=1.5148, P=0.1728\right)$. After the move to the $37.85 \mathrm{~L}$ tank, pupfish in the rearing buckets were allowed to acclimate for $40 \mathrm{~min}$ before beginning observations. The two buckets were then videotaped simultaneously from above using a digital video camera (Sony DCR-TRV 19) mounted on a tripod. All video recordings lasted for 25-30 min and were made between the hours of 14:00 and 17:00. An observer later watched the videotapes and scored the frequency of aggressive charges and nips (combined) that occurred over $20 \mathrm{~min}$. All videotapes were coded so that the observer was unaware of treatment when scoring behaviors.

\section{AVT immunocytochemistry}

At 17-23 weeks of age, one male pupfish from each treatment bucket was collected for measurement of brain AVT immunocytochemistry. This male was always the largest male in the bucket, and all males were sexually mature when they were collected. Sexual maturity was determined by display of bright blue body coloration characteristic of reproductively active males (Kodric-Brown, 1978). Sample sizes for AVT immunoreactivity were $n=6-14$ replicate rearing buckets per treatment (Table 1), and consisted of a subset of the same buckets used for behavioral observations.

Males were collected between the hours of 13:00 and 15:00 from 20 April to 7 July, 2004. Fish were euthanized in MS222, and the brain was exposed by removing the top of the cranium with forceps. Less than $15 \mathrm{~s}$ after removal from the MS222, the fish was submerged in 4\% paraformaldehyde in phosphatebuffered saline (PBS) for $24 \mathrm{~h}$ on ice. Brains were then dissected and cryoprotected first in 4\% paraformaldehyde with 30\% sucrose in PBS and then in $30 \%$ sucrose in PBS, each for $24 \mathrm{~h}$ at $4{ }^{\circ} \mathrm{C}$. Brains were subsequently frozen on dry ice and stored at $-80{ }^{\circ} \mathrm{C}$.

Tissue was embedded in cryomatrix (Shandon, Pittsburgh, PA), frozen, and transversally sectioned $(30 \mu \mathrm{m})$ at $-19^{\circ} \mathrm{C}$ using a cryostat (Microm HM $505 \mathrm{~N}$ ). Following drying on a warmer plate, slides were blotted with filter paper, immersed in phosphate buffer (PB) for $10 \mathrm{~min}$, dried at room temperature, and again blotted with filter paper to ensure tissue adherence.

The protocol for AVT immunocytochemistry was adapted from a procedure by Goodson and Bass (2000) and described in further detail by Lema and Nevitt (2004a). Treatments were balanced in each AVT immunocytochemistry run to control for inter-run variation in the intensity of immunoreactive staining. Slides were first immersed in $0.025 \% \mathrm{H}_{2} \mathrm{O}_{2}$ to eliminate endogenous peroxidases. Slides were then blocked with $10 \%$ normal goat serum, and anti-AVT antiserum (R-82 antiserum, kindly provided by Dr. F. van Leeuwen, Netherlands Institute for Brain Res., Amsterdam) was applied at a dilution of 1:4000 in PBS with 0.3\% Triton X-100 and $0.01 \%$ sodium azide for $16-18 \mathrm{~h}$ at $4{ }^{\circ} \mathrm{C}$. This anti-AVT antiserum has previously been shown to label AVT in brain tissue from a variety of taxa including fish and amphibians (Goodson and Bass, 2000; Moore et al., 2000). Secondary antibody binding was visualized by incubation with an avidinbiotin-peroxidase complex (rabbit IgG ABC Elite Kit, Vector Laboratories) and diaminobenzidine (DAB; Sigma, St. Louis, MO, USA). Sections were then dehydrated in a graded ethanol series and cleared in xylene before being coverslipped with Cytoseal 60 (Stephens Scientific). Preincubation of antiserum with vasotocin (10 $\mu \mathrm{M}$ and $100 \mu \mathrm{M}$ for $30 \mathrm{~h}$; Sigma) eliminated immunohistochemical staining, while preincubation with the related fish neuropeptide isotocin (10 $\mu \mathrm{M}$ and $100 \mu \mathrm{M}$ for $30 \mathrm{~h}$; Sigma) failed to block staining. Sections run with exclusion of anti-AVT antiserum showed no DAB staining.

\section{Quantification of AVT immunoreactivity}

AVT-immunoreactive (AVT-ir) neuron number and size were quantified in all serial sections using AxioVision software (Carl Zeiss, Oberkochen, Germany). Digital images of sections were captured by digital camera (Axiocam, Carl Zeiss) attached to a bright-field, light microscope (Axioskop, Carl Zeiss). For analysis, neurons from the nucleus preopticus parvocellularis anterioris, nucleus preopticus parvocellularis posterioris, and nucleus preopticus magnocellularis pars parvocellularis were grouped as parvocellular neurons.
AVT-ir neurons within the nucleus preopticus magnocellularis pars magnocellularis and pars gigantocellularis were analyzed as magnocellular neurons. Neurons were classified by their morphology and neuroanatomical location (Peter et al., 1975; Braford and Northcutt, 1983). Nomenclature of preoptic regions follows descriptions by Braford and Northcutt (1983).

Methods for quantifying AVT-ir cell number and size followed established protocols used previously in similar studies with other species (Foran and Bass, 1998; Miranda et al., 2003). The number of parvocellular and magnocellular AVT-ir neurons was determined by counting all preoptic AVT-ir neurons that showed a distinct cell border and at least one neurite. AVT-ir neuron size was measured as the cross-sectional area of an AVT-ir cell by tracing the cell soma's profile with a digitizing pen. Only cells displaying a distinct axon or dendrite were measured. Soma area $\left(\mu \mathrm{m}^{2}\right)$ or 'neuron size' was automatically calculated by the AxioVision software, which had been calibrated with a micrometer. For each fish, I measured the size of $76 \pm 2$ (mean $\pm \mathrm{SE}$; range, 38 to 117) parvocellular vasotocin-ir neurons and $43 \pm 2$ (range, 20 to 103) magnocellular neurons. There was no difference among treatments in the mean number of parvocellular neurons (one-factor ANOVA, $F_{7,71}=1.6491, P=0.1379$ ) or magnocellular neurons $\left(F_{7,71}=0.9239, P=0.4942\right)$ that were measured. Brain tissue was sectioned at $30 \mu \mathrm{m}$ and immersed in anti-AVT antiserum while mounted on slides, so it is unlikely that any AVT neuron was measured in more than one section. Reported values are the mean AVT-ir neuron size for each fish.

\section{Statistical analyses}

I first used a three-factor analysis of variance (ANOVA) model to determine whether the frequency of aggressive behaviors (aggressive charges and nips combined) was affected by population origin, salinity, temperature regime, or any interaction between these factors. I then used analysis of covariance (ANCOVA) models to determine whether the number and size of AVT-ir neurons in the parvocellular and magnocellular regions were influenced by population origin, salinity, or temperature. Body mass was used as a covariate in these analyses since body size differed between both population and salinity treatments (ANOVA, population effect: body mass, $F_{1,64}=8.0356, P=0.0061$; standard length, $F_{1,64}=14.1423, P=0.0004$; salinity effect: body mass, $F_{1,64}=6.2899, P=0.0147$; standard length, $\left.F_{1,64}=3.4800, P=0.0667\right)$. For each ANCOVA model, backward elimination was used to remove interactions that had $F$ values less than 1.0 in the model. Only statistically significant interactions from these ANCOVA models are presented. Lastly, I used ANCOVA models to test whether the size and number of parvocellular and magnocellular AVT neurons were related to the frequency of aggressive behaviors in the rearing environment and whether any such relationship differed between populations. All statistical tests were two-tailed, and all analyses were performed using JMP 4.0.2 software (SAS Institute, Inc.).

\section{Results}

\section{Populations differ in aggression}

The frequency of aggressive behaviors varied among treatments (Table 1). Pupfish from Big Spring showed a higher frequency of aggressive charges and nips than did pupfish from the Amargosa River (Fig. $3 \mathrm{~A} ; F_{1,87}=10.8106, P=0.0015$ ). Temperature regime of the rearing environment also affected the frequency of aggressive behaviors, with pupfish reared under a fluctuating temperature regime showing higher aggression than fish reared under a stable temperature regime (Fig. 3B; $\left.F_{1,87}=8.3196, P=0.0049\right)$.

\section{Populations differ in neural AVT phenotype}

Immunoreactivity to AVT was evident in cell bodies and fibers by their staining with the brown, diaminobenzidine reaction precipitate. Neuronal bodies that stained positive for 

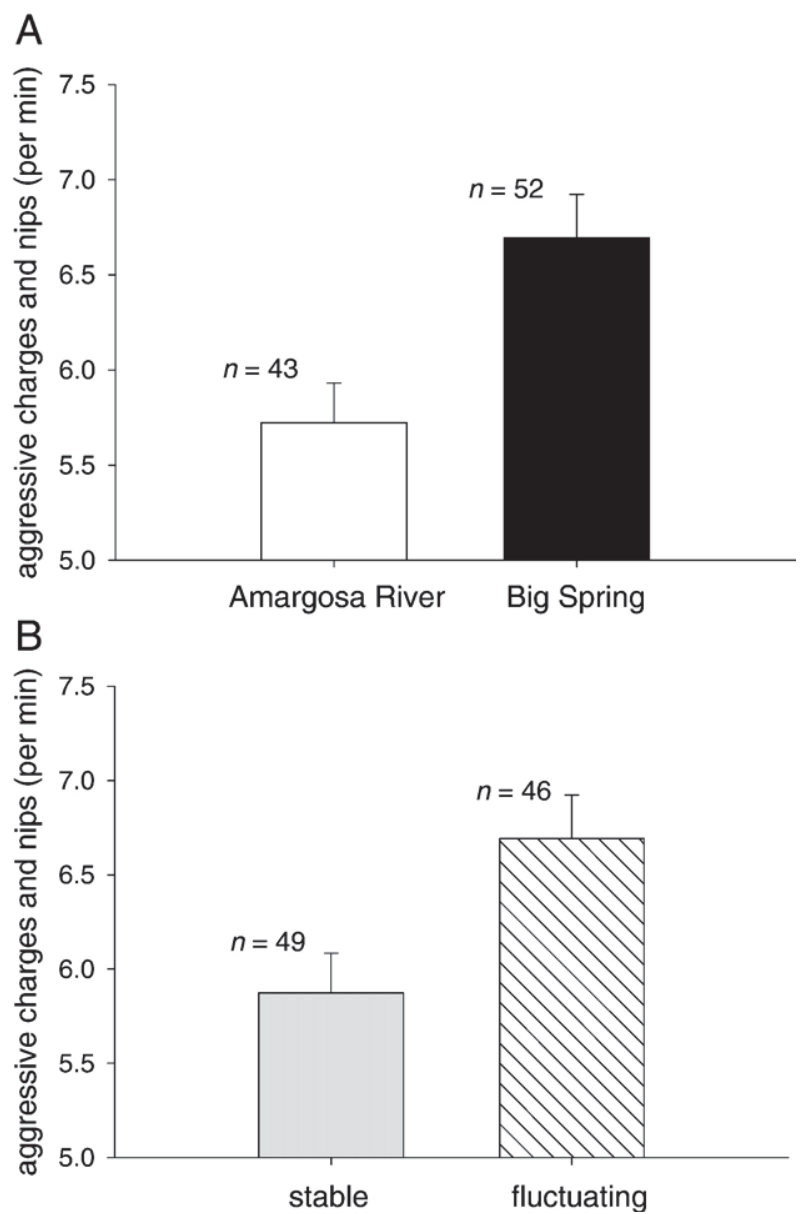

Fig. 3. (A) Social groups of pupfish from Big Spring were more aggressive than social groups from the Amargosa River (population effect, $P=0.0015$ ). (B) The temperature regime of the rearing environment also affected the frequency of aggressive behaviors (temperature effect, $P=0.0049$ ), with pupfish from both populations behaving more aggressively when reared under a daily fluctuating temperature. Data are shown as mean $\pm \mathrm{SE}$.

AVT were restricted to the preoptic area of the hypothalamus, and corresponded to the distribution described previously in wild Amargosa pupfish (Lema and Nevitt, 2004a) and other fishes (Goodson and Bass, 2000; Parhar et al., 2001; Semsar and Godwin, 2003; Saito et al., 2004). The most anteriorly located AVT neurons were found in the nucleus preopticus parvocellularis anterioris. More posteriorly, cell bodies positive for AVT-ir were localized to the nucleus preopticus parvocellularis posterioris (PPp), nucleus preopticus magnocellularis pars magnocellularis $(\mathrm{PMm})$, and the nucleus preopticus magnocellularis pars gigantocellularis (PMg) (Figs. 4A-C). Vasotocin fibers in the pituitary-hypophyseal tract (PHT) (Fig. 4D) extended posteriorly to innervate the pituitary. AVT-ir staining was located in the same brain regions in all treatments.

Table 1 provides a summary of mean $( \pm \mathrm{SE})$ values for AVTir neuron number and size among treatments. Morphometric comparison of AVT-ir neurons revealed that populations differed in the size and number of AVT neurons in the parvocellular and magnocellular regions of the preoptic area. Males from Big Spring had larger parvocellular AVT-ir neurons than Amargosa River males (Fig. 5A; $F_{1,66}=6.2725$, $P=0.0147$ ), even though both populations showed a positive association between neuron size and body mass $\left(F_{1,66}=9.4012\right.$, $P=0.0031)$. Populations also differed in the size of magnocellular AVT-ir neurons, although this difference was expressed as a change in the trajectory of neuron size relative to body size (Fig. $5 \mathrm{~B} ; F_{1,59}=4.1531, P=0.0460$ ). Male pupfish from the Amargosa River population also had more parvocellular AVT-ir neurons (AR, $97.9 \pm 4.0$; BS, $82.7 \pm 4.3$; $F_{1,61}=6.4930, P=0.0133$ ), but fewer magnocellular AVT-ir neurons (AR, $47.1 \pm 2.3$; BS, $53.4 \pm 2.3 ; F_{1,65}=4.7502$, $P=0.0329)$ than males from Big Spring. The number of AVT-ir neurons in the magnocellular region was positively related to body mass in both populations $\left(F_{1,65}=48.3969, P<0.0001\right)$.

\section{Plasticity of parvocellular vasotocin neurons differs between populations}

Salinity affected the number of AVT-ir parvocellular neurons, but the direction of this effect differed between populations (Fig. $\left.6 \mathrm{~A} ; F_{1,61}=4.4303, P=0.0394\right)$. In the 3 ppt environment, males from the Big Spring and Amargosa River populations showed a similar number of parvocellular AVT-ir neurons. Yet, the number of AVT-ir neurons decreased under 0.4 ppt salinity in Big Spring fish, but increased in Amargosa River fish. These populations also showed a near-significant tendency toward differing in how the size of parvocellular AVT-ir neurons responded to temperature (Fig. $6 \mathrm{~B} ; F_{1,66}=3.8649, P=0.0535$ ).

Temperature-dependent effects of salinity on magnocellular vasotocin neurons

Salinity had significant effects on the number and size of magnocellular AVT-ir neurons in the preoptic area. Males from both populations had fewer magnocellular AVT-ir neurons in the $3 \mathrm{ppt}$ salinity environment than in the $0.4 \mathrm{ppt}$ environment (Fig. 7A; $F_{1,65}=19.5821, P<0.0001$ ). The size of these magnocellular AVT-ir neurons was also altered by salinity, although the direction of this change depended on the temperature regime that the fish experienced (Fig. 7B, salinity $*$ temperature interaction, $F_{1,59}=4.0230, P=0.0494$ ).

Neural AVT phenotype is related to aggression in the rearing environment

Neural AVT-ir phenotype in both populations showed a relationship with the frequency of aggressive behaviors in the rearing environment. Variation in parvocellular AVT-ir neuron size was significantly associated with the rate of aggression in the rearing environment, with males from more aggressive environments having smaller parvocellular AVT-ir neurons in both populations (Fig. 8A; aggression effect; $\left.F_{1,68}=10.2015, P=0.0021\right)$. Populations differed, however, in how the size of magnocellular AVT-ir neurons related to the frequency of aggressive behaviors (Fig. 8B; aggression $*$ population interaction; $\left.F_{1,68}=4.8663, P=0.0308\right)$. There were no significant relationships between aggression 

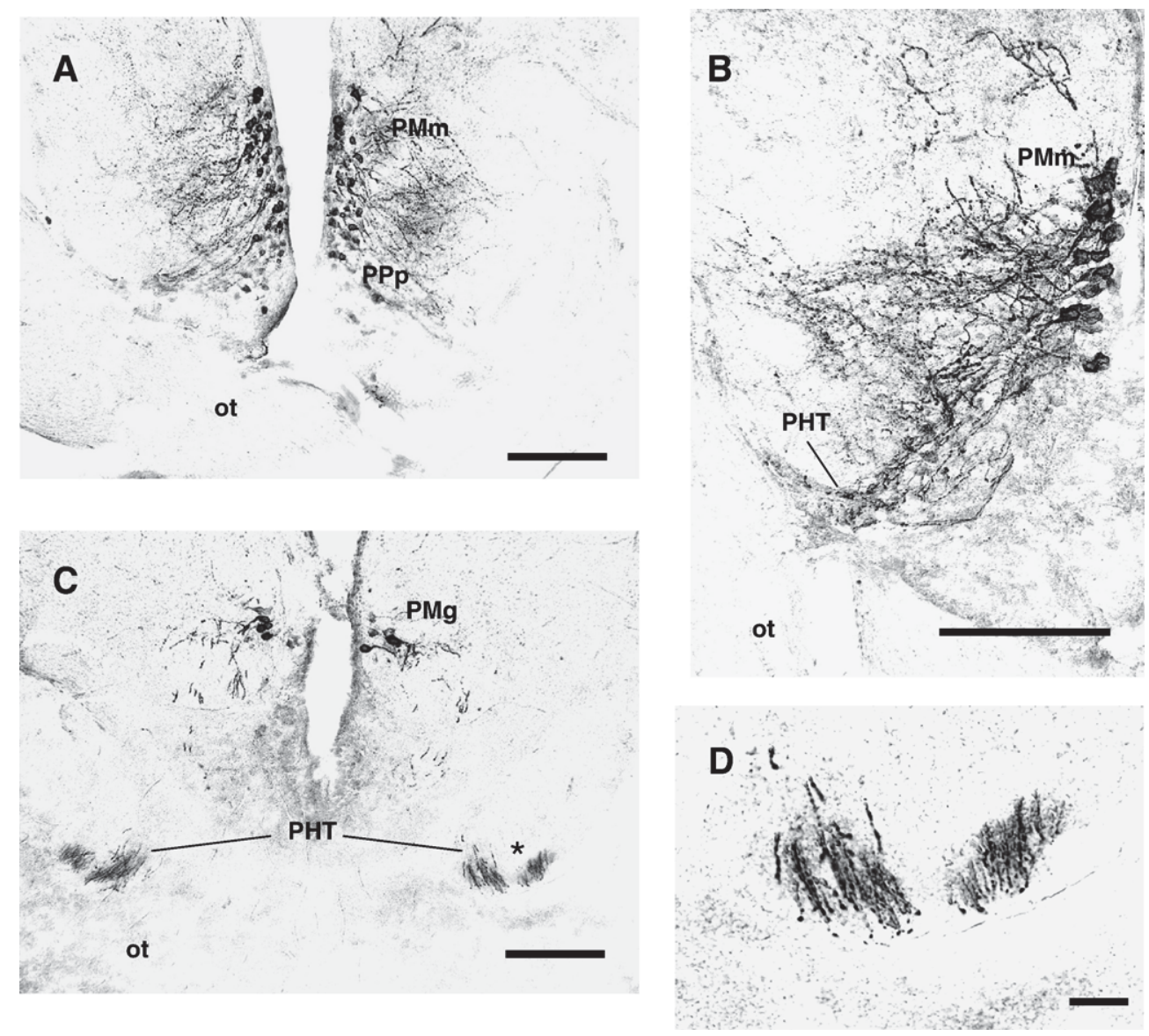

Fig. 4. Representative images of AVT immunoreactive staining in the pupfish preoptic area. (A) AVT neurons within the nucleus preopticus parvocellularis posterioris (PPp) and nucleus preopticus magnocellularis pars magnocellularis (PMm). (B) AVT immunoreactive neurons in the nucleus preopticus magnocellularis pars magnocellularis (PMm) showing nerve fibers innervating the pituitary-hypophyseal tract (PHT). (C) AVT staining in the PHT and gigantocellular region of the nucleus preopticus magnocellularis (PMg). (D) Higher magnification view of PHT marked by asterisk in panel C. Additional abbreviation: ot, optic tract. Scale bars represent $100 \mu \mathrm{m}(\mathrm{A}-\mathrm{C})$ and $20 \mu \mathrm{m}(\mathrm{D})$.

rate in the rearing environment and either the number of parvocellular AVT-ir neurons or the number of magnocellular AVT-ir neurons.

\section{Discussion}

This study provides the first evidence that environmental responsiveness of the AVT system can evolve between wild populations that occupy ecologically dissimilar habitats. The Big Spring and Amargosa River populations of C. nevadensis were previously found to vary in preoptic AVT expression in the wild (Lema and Nevitt, 2004a), but it remained unknown whether this difference resulted from phenotypic plasticity, genetic differentiation, or a combination of these influences. Here I found that pupfish from these populations continued to differ in neural AVT phenotype when reared in commongarden environments. This population difference included a change in how the AVT system responded to environmental conditions. Preoptic AVT neuron number and size showed plastic responses to salinity and temperature in both populations, but populations differed in how these factors affected the AVT system. This work also shows for the first time that some of the variation in neural AVT phenotype may be related to the level of aggression experienced during development.

The population differences and plastic responses in AVT neuron number and size seen here likely reflect changes in the production and release of AVT from the preoptic area. Given the considerable plasticity in this hormone system, these differences could have resulted from developmental plasticity over ontogeny or from shorter-term acute physiological responses of AVT neurons. All the same, pupfish in the present study were reared in a common laboratory environment. It is thus likely that the population differences in how the AVT system responds to physical and social conditions are in part genetically based, and that the AVT system in these populations has shown divergent evolution in allopatry. While other studies have established that environmental conditions influence hormonal and neural phenotypes in the laboratory (Francis et al., 1993; Hofmann and Fernald, 2000; van Praag et al., 2000; Lema et al., 2005), this work provides evidence that genetic differences in plasticity may contribute to population variation in these phenotypes. 


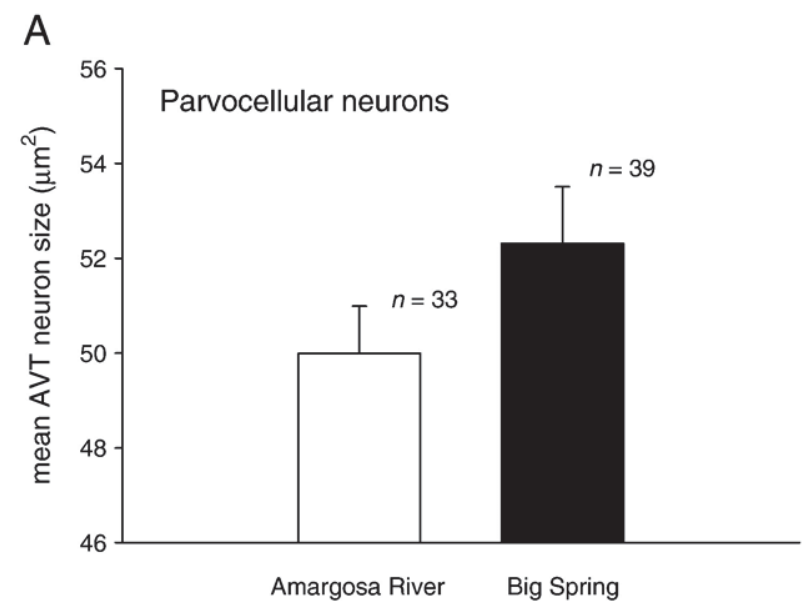

B

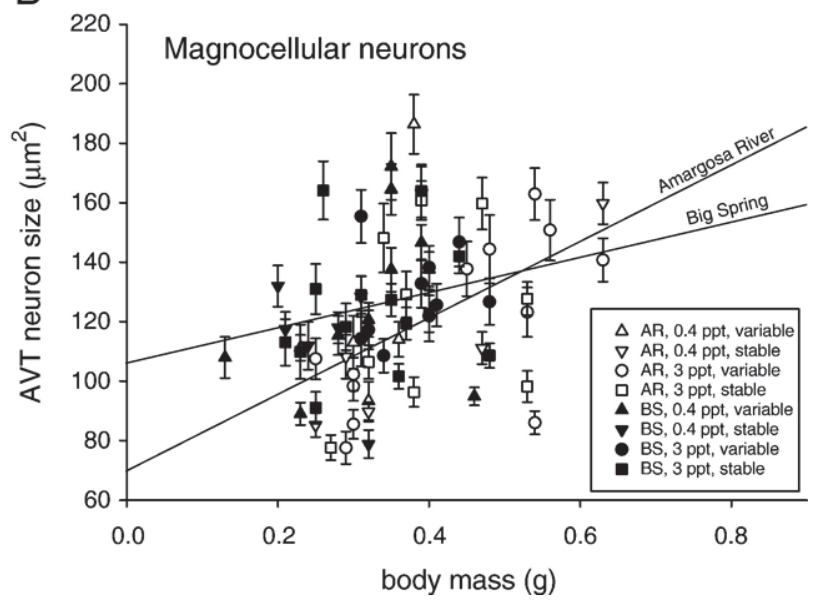

Fig. 5. Populations differed in AVT neuron size. (A) The size of parvocellular AVT neurons was greater in males from Big Spring then in males from the Amargosa River (population effect, $P=0.0147$ ). Values show mean \pm SE. (B) Populations differ in how the size of magnocellular AVT neurons change with body size (population * body mass interaction effect, $P=0.0460$ ).

\section{Population differences in aggression}

The Big Spring and Amargosa River populations of $C$. nevadensis differ in the frequency of aggressive and courtship behaviors in the wild (Soltz, 1974; Kodric-Brown, 1981; Soltz and Hirshfield, 1981), but it was not known whether these differences had a genetic basis. Here, small social groups of pupfish from Big Spring had higher rates of aggression compared to groups from the Amargosa River when all fish were bred and reared under similar conditions in the laboratory. This result suggests that the Big Spring and Amargosa River populations have evolved differences in aggression.

A number of ecological differences between Big Spring and the Amargosa River might have caused these populations to diverge in aggressive behaviors. Adult male pupfish establish and defend breeding territories over heterogeneous or rocky substrate which females prefer for spawning (Kodric-Brown, 1978). The availability of such high quality spawning substrate differs between the Big Spring and Amargosa River habitats (Soltz, 1974), and differences in competition for breeding territories may have selected for aggression differences in these populations. Given the ecological variation between these habitats, it is also possible that there are differences in competition for food resources or foraging microhabitats among juvenile pupfish that generate dissimilar selective pressures on aggression. Currently, however, little is known about how juvenile pupfish behave in the Big Spring and Amargosa River habitats, and future field studies are needed to further explore this idea.

\section{Association between the AVT system and aggression}

In this experiment, neural AVT phenotypes of male pupfish sampled after sexual maturity showed a relationship with the level of aggression in the environment earlier in development. Parvocellular AVT neuron size declined with elevated aggression in the rearing environment in both populations. Magnocellular AVT neuron size, in contrast, was smaller in fish that experienced higher aggression for Amargosa River pupfish but not for Big Spring pupfish, indicating that aggression
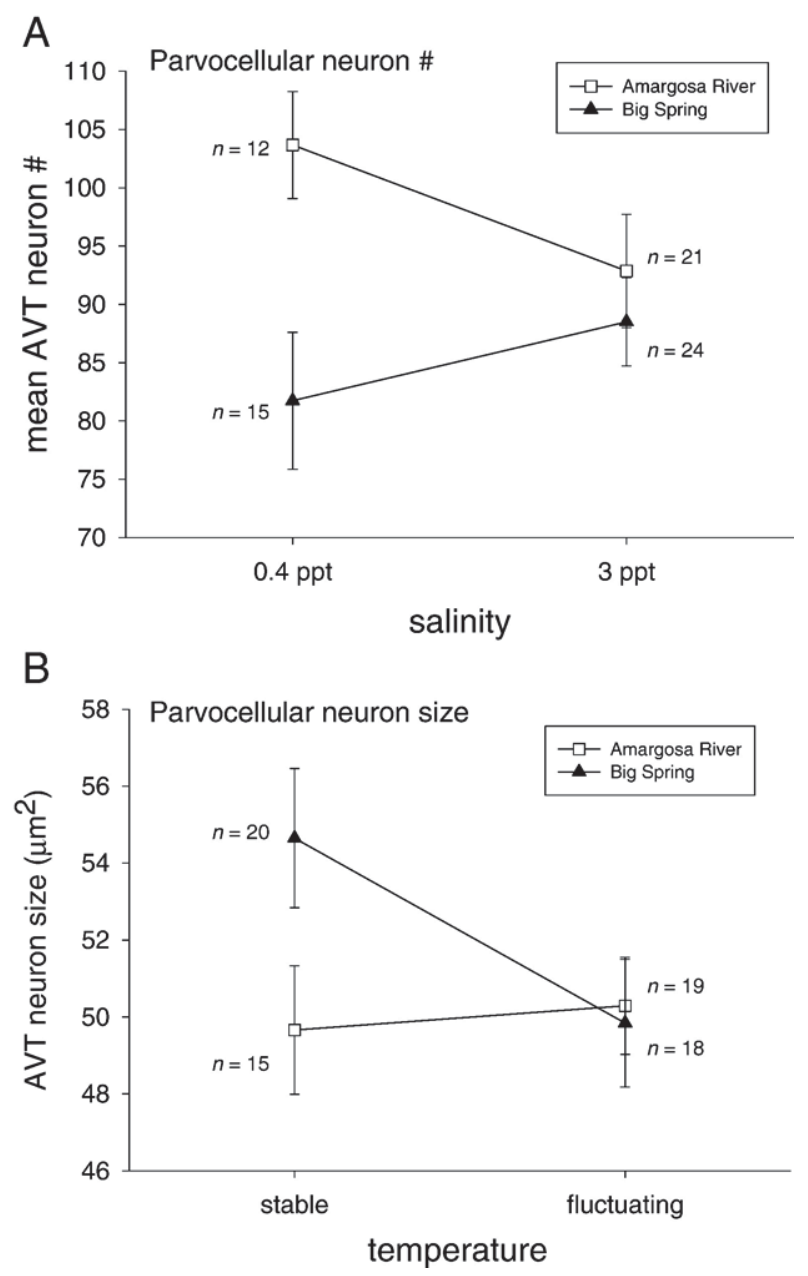

Fig. 6. Populations differed in plasticity of parvocellular AVT neurons. (A) Parvocellular AVT neuron number responded differently to salinity in the Big Spring and Amargosa River populations $(P=0.0394)$. (B) Populations showed a near-significant tendency toward differing in how the size of parvocellular AVT neurons changed with temperature regime of the rearing environment $(P=0.0535)$. 

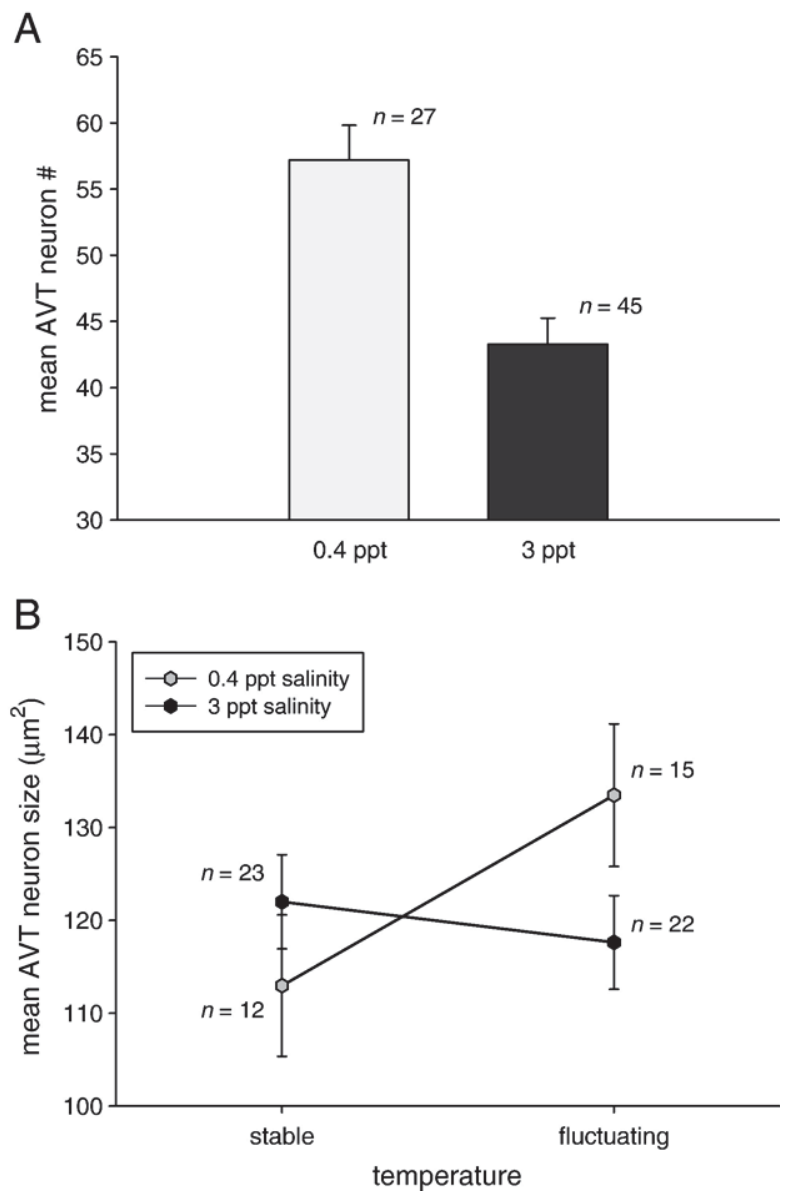

Fig. 7. Salinity affected the number and size of magnocellular AVT neurons. (A) Elevated salinity reduced the number of magnocellular AVT neurons in both populations $(P<0.0001)$. (B) Salinity also altered the size of magnocellular AVT neurons, but the direction of this effect depended on temperature $(P=0.0494)$. These effects of salinity were similar in both pupfish populations.

experienced early in life may impact neural AVT phenotype differently in populations from ecologically dissimilar habitats. Aggression measurements in the current study were collected on social groups and not on individuals, so it is difficult to determine why there was an association between aggression and neural AVT phenotype. The association could indicate a direct cause-effect relationship between AVT production and aggressive behavior, or could represent a shift in neural AVT phenotype caused by stress from elevated social conflict. Direct links between immunoreactive AVT expression and aggression can be elusive even when these phenotypes are measured on the same individuals, and AVT gene expression may be a better indicator of behavioral state than immunoreactive AVT soma size (Semsar and Godwin, 2003). Nevertheless, the results of the current study do suggest that social experience regulates magnocellular AVT phenotype differently in the Big Spring and Amargosa River populations.

The adaptive significance of these population differences in the AVT system is not entirely clear since only two populations were compared (Garland and Adolph, 1994). Nevertheless, the behavioral and physiological roles of AVT do provide hints to what these differences in neural AVT phenotype might mean functionally. Exogenous AVT has been shown to modulate aggression in pupfish (Lema and Nevitt, 2004b) and agonistic and reproductive behaviors in other fishes (Bastian et al., 2001; Semsar et al., 2001; Salek et al., 2002; Carneiro et al., 2003; Thompson and Walton, 2004). Variation in brain AVT expression has also been found to be associated with social status and alternative reproductive phenotypes in fish (Foran and Bass, 1998; Grober et al., 2002; Miranda et al., 2003; Larson et al., 2006). In the teleost brain, AVT receptors have been localized to the telencephalon (Moons et al., 1989), and projections from preoptic AVT neurons clearly extend forward into this region (Saito et al., 2004). Taken together, these findings suggest that AVT released from forebrain projections may act on neural substrates to modulate behavior.

Social behaviors in pupfish are responsive to the environment (Kodric-Brown, 1981; Watters et al., 2003), and there is some preliminary evidence suggesting that the Big Spring and Amargosa River populations may differ in how they respond behaviorally to changes in social conditions. In an unpublished behavioral study, the breeding system (i.e., territorial, group
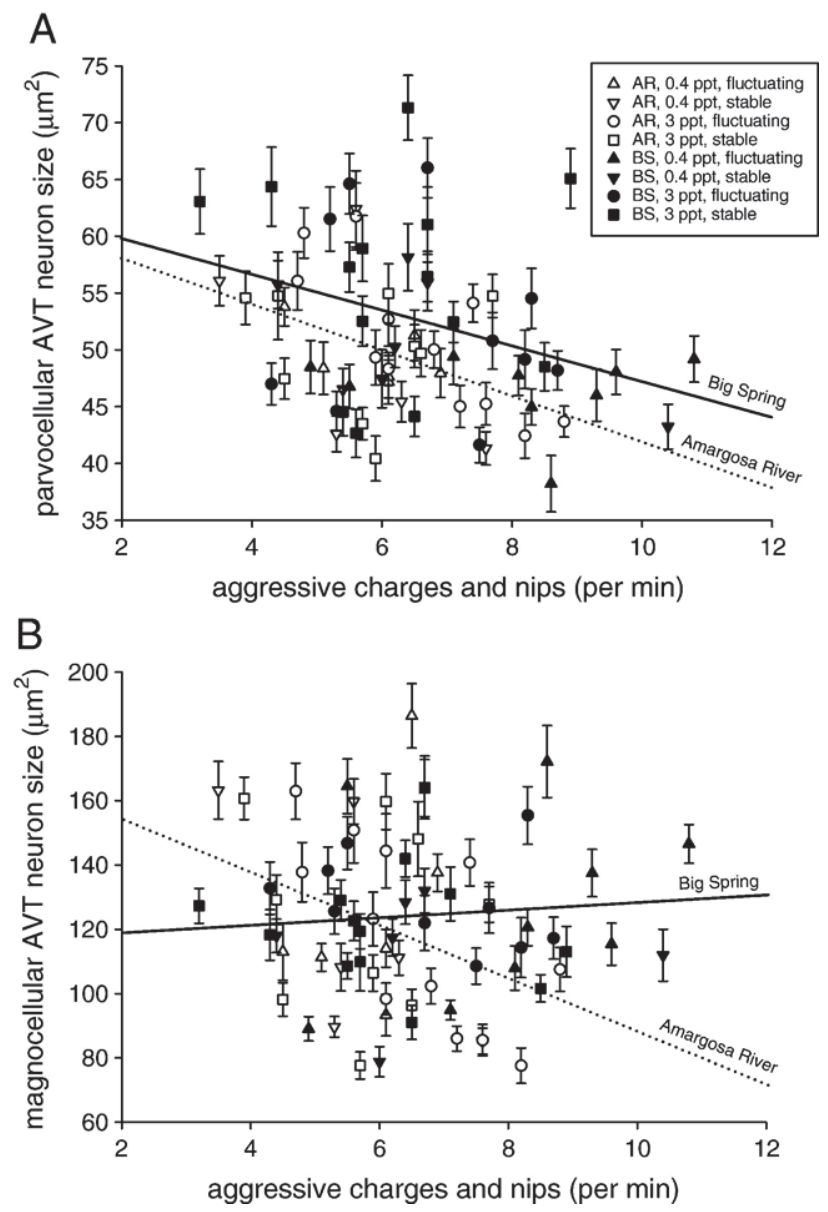

Fig. 8. Neural AVT phenotype at sexual maturity (16-23 weeks of age) showed a relationship with the level of aggression in the rearing environment earlier in development (at 8-9 weeks of age). (A) Parvocellular AVT neuron size decreased similarly with elevated aggression in the rearing environment in both populations $(P=0.0021)$. (B) The size of magnocellular AVT neurons decreased with elevated aggression in male pupfish from the Amargosa River, but not in males from Big Spring $(P=0.0308)$. 
spawning) of groups of pupfish from the Big Spring and Amargosa River habitats responded differently to changes in social density (described on p. 310 in Soltz and Hirshfield, 1981). Although additional studies are needed to validate this early work, the population differences in socially induced magnocellular AVT neuron size seen here could in part mediate the dissimilar behavioral responses of these populations to social conditions.

\section{Salinity and temperature regulation of the AVT system}

In this study, neural AVT phenotype was also found to be influenced by the physical environment. In both populations, elevated salinity decreased the number of magnocellular AVT neurons, while interacting with temperature to increase magnocellular AVT neuron size under a stable temperature but decrease neuron size under a fluctuating temperature. In teleost fish, AVT regulates hydromineral balance by acting on the gills and kidneys (Balment et al., 1993; Warne, 2002). Exogenous AVT stimulates $\mathrm{Cl}^{-}$secretion in cultured gill cells from sea bass (Avella et al., 1999), and AVT binding activity and AVT (V1-type) receptor mRNA transcripts have been found in gill tissues from this and other species (Mahlmann et al., 1994; Guibbolini and Avella, 2003). In the kidneys, AVT decreases urine production and increases water reabsorption in an antidiuretic response (Warne, 2002). Corresponding with these osmoregulatory functions, neural AVT phenotype has been shown to respond to salinity in a variety of fish species (i.e., Nürnberger et al., 1996; Hyodo et al., 2004). For example, freshwater acclimated rainbow trout (Oncorhynchus mykiss) decrease AVT mRNA production in magnocellular neurons when transferred to $80 \%$ seawater (Hyodo and Urano, 1991). This salinity-induced alteration in preoptic AVT expression is paralleled by a change in AVT levels in blood plasma (Kulczykowska, 1997, 2001). The results presented here with pupfish, however, provide the first evidence that temperature can interact with salinity to influence magnocellular AVT neurons.

Parvocellular AVT neurons also showed plastic responses to the physical environment. It is clear from other studies that parvocellular AVT neurons respond to stressful stimuli. In rainbow trout (Oncorhynchus mykiss), acute confinement stress increases AVT gene expression in parvocellular neurons but not magnocellular neurons. Chronically repeating this confinement stress over several days, however, eventually decreases AVT gene expression in parvocellular neurons (Gilchriest et al., 2000). AVT modulates adrenocorticotropin (ACTH) release from the pituitary in fish (Baker et al., 1996), suggesting that AVT may play a role in how fish respond to stressors. Pupfish from the Amargosa River population showed less plasticity in parvocellular AVT neurons than pupfish from Big Spring. Amargosa River pupfish live in a highly variable environment, and changes in environmental conditions in this habitat may be unpredictable. The population differences in plasticity of parvocellular neurons may thus be an evolutionary change caused by the distinct physiological challenges of their habitats.

\section{Plasticity and AVT phenotype in wild pupfish}

Based on the data presented here, the differences in neural AVT phenotype seen previously between the wild Big Spring and Amargosa River populations cannot be attributed solely to a genetically fixed, evolved difference or to a plastic response of the AVT system to dissimilar habitat conditions. Rather, variation in neural AVT phenotype between the wild populations appears to be caused by genetically based population differences in plasticity of the AVT system and the response of the AVT system in these populations to the respective physical and social conditions of their habitats.

Accordingly, plasticity in the AVT system helps explain some aspects of the population variation in AVT phenotype seen in the wild. When differences in the AVT system were documented between the wild populations, Big Spring had a stable temperature and 0.4 ppt salinity while the Amargosa River had a fluctuating temperature and $1.8 \mathrm{ppt}$ salinity (Lema and Nevitt, 2004a). Based on the plasticity seen here, wild fish under these conditions in the Amargosa River (1.8 ppt salinity, variable temperature) would be expected to have larger magnocellular AVT neurons compared to fish from Big Spring (0.4 ppt salinity, stable temperature) (see Fig. 7B). Indeed, such a difference was found in the comparison of wild populations (Lema and Nevitt, 2004a). Similarly, wild males from the Amargosa River had larger parvocellular AVT neurons than wild males from Big Spring. Rates of aggression can be higher in the Big Spring habitat, and this elevated aggression may contribute to smaller parvocellular AVT neurons in Big Spring fish (see Fig. 8A).

Other aspects of the differences in AVT phenotype between wild populations, however, do not appear to be readily explained by the plasticity seen here. For example, wild males from these populations had similar numbers of magnocellular neurons (Lema and Nevitt, 2004a). Yet, captively reared males from Big Spring had more magnocellular AVT neurons than Amargosa River males, and this discrepancy does not appear to be explained by the effects of temperature or salinity. Likewise, pupfish from the wild populations had similar numbers of parvocellular AVT neurons, but Amargosa River males had more parvocellular AVT neurons in the laboratory. Certainly, there are other environmental factors not examined here that may affect the AVT system, and it is likely that multiple environmental cues interact to shape neural AVT phenotype in the wild. The timing of exposure to these environmental factors may also be important for AVT phenotype. Pupfish from all treatments were raised under similar conditions as embryos, and these early rearing conditions may have affected behavior or AVT physiology of pupfish from the populations differently. Moreover, the parents of fish used in this experiment were collected from the wild and maintained in captivity prior to breeding. Although maternal effects have not yet been found for the AVT system of fish, maternal influences resulting from exposure to the differing conditions of their habitats, or to the laboratory housing conditions, could affect the AVT phenotype and behavior of offspring. It is also important to note that the current assessment 
of population variation in AVT phenotype in the wild is based on a single study (Lema and Nevitt, 2004a). AVT neuron number and size likely change quickly in wild pupfish, and additional work is needed to fully characterize neural AVT phenotypes in the wild populations.

\section{Conclusions}

Although it is clear that populations can evolve differences in behavior quickly, we are only beginning to appreciate the complex physiology behind such changes. From this work, it is now evident that divergence in the environmental responsiveness of one hormonal pathway known to underlie social behaviors - the AVT system - can arise quickly in wild populations. This work also demonstrates that plasticity in the preoptic AVT system can evolve in a region-specific manner for distinct neural groups that express this hormone, and illustrates how individual variation in neural AVT phenotype is shaped by interacting influences from the physical and social environment. Taken together, these results suggest that population differences in how the AVT system responds to salinity, temperature, and social conditions could contribute to the variation in neural AVT phenotype, and possibly the differences in social behavior, seen between $C$. nevadensis populations in the wild. Future studies testing for an association between preoptic AVT expression and social behaviors in the wild should thus consider not only the organism's current behavior, but also the physical and social conditions that the organism experienced earlier in development (see also, Semsar and Godwin, 2003).

\section{Acknowledgments}

This research was supported by an NSF Graduate Research Fellowship and a UC Davis Summer Research Fellowship. Additional support was provided by NIH (PHS DCO3174). I am grateful to G.A. Nevitt for advice throughout this work, and to J.L. DeBose, R.L. Kihslinger, and G.B. Cunningham for assistance with animal care. I also thank Dr. F. van Leeuwen for kindly providing the R-82 AVT antibody. Pupfish were collected under permission of the US Fish and Wildlife Service (TE031898-0), Ash Meadows National Wildlife Refuge (14554-00004), US Bureau of Land Management (CA-680.32 and CA-680.38), Nevada Division of Wildlife (S 21526), and California Department of Fish and Game (803065-04 and 803006-02). I also thank J.L. DeBose, D.N. Reznick, and two anonymous reviewers for their insightful comments on previous versions of the manuscript.

\section{References}

Avella, M., Part, P., Ehrenfeld, J., 1999. Regulation of $\mathrm{Cl}-$ secretion in seawater fish (Dicentrarchus labrax) gill respiratory cells in primary culture. J. Physiol. (London) 516, 353-363.

Baker, B.I., Bird, D.J., Buckingham, J.C., 1996. In the trout, CRH and AVT synergize to stimulate ACTH release. Regul. Pept. 67, 207-210.

Balment, R.J., Warne, J.M., Tierney, M., Hazon, N., 1993. Arginine vasotocin and fish osmoregulation. Fish Physiol. Biochem. 11, 189-194.

Bastian, J., Schniederjan, S., Nguyenkim, J., 2001. Arginine vasotocin modulates a sexually dimorphic communication behavior in the weakly electric fish Apteronotus leptorhynchus. J. Exp. Biol. 204, 1909-1923.

Braford Jr., M.R., Northcutt, R.G., 1983. Organization of the diencephalon and pretectum of the ray-finned fishes. In: Northcutt, R.G., Davis, R.E. (Eds.), Fish Neurobiology, vol. 2. Univ. of Michigan Press, Ann Arbor, pp. 117-163.

Carneiro, L.A., Oliveira, R.F., Canário, A.V.M., Grober, M.S., 2003. The effect of arginine vasotocin on courtship behaviour in a blenniid fish with alternative reproductive tactics. Fish Physiol. Biochem. 28, 241-243.

Carroll, S.P., Corneli, P.S., 1999. The evolution of behavioral norms of reaction as a problem in ecological genetics: theory, methods, and data. In: Foster, S.A., Endler, J.A. (Eds.), Geographic Variation in Behavior: Perspectives on Evolutionary Mechanisms. Oxford University Press, Oxford, UK, pp. 52-68.

Doughty, P., Reznick, D.N., 2004. Patterns and analysis of adaptive phenotypic plasticity in animals. In: Dewitt, T.J., Scheiner, S.M. (Eds.), Phenotypic Plasticity: Functional and Conceptual Approaches. Oxford Univ. Press, Oxford, UK, pp. 126-150.

Enzel, Y., Wells, S.G., 1997. Extracting Holocene paleohydrology and paleoclimatology information from modern extreme flood events: an example from southern California. Geomorphology 19, 203-226.

Foran, C.M., Bass, A.H., 1998. Preoptic AVT immunoreactive neurons of a teleost fish with alternative reproductive tactics. Gen. Comp. Endocrinol. 111, 271-282.

Foster, S.A., 1999. The geography of behaviour: an evolutionary perspective. Trends Ecol. Evol. 14, 190-195.

Francis, R.C., Soma, K., Fernald, R.D., 1993. Social control of the brainpituitary-gonadal axis. Proc. Natl. Acad. Sci. U. S. A. 90, 7794-7798.

Garland, T., Adolph, S.C., 1994. Why not to do 2 species comparative studies: limitations on inferring adaptation. Physiol. Zool. 67, 797-828.

Gilchriest, B.J., Tipping, D.R., Hake, L., Levy, A., Baker, B.I., 2000. The effects of acute and chronic stresses on vasotocin gene transcripts in the brain of the rainbow trout (Oncorhynchus mykiss). J. Neuroendocrinol. 12, 795-801.

Gilmour, K.M., DiBattista, J.D., Thomas, J.B., 2005. Physiological causes and consequences of social status in salmonid fish. Integr. Comp. Biol. 45, $263-273$.

Goodson, J.L., Bass, A.H., 2000. Vasotocin innervation and modulation of vocal-acoustic circuitry in the teleost Porichthys notatus. J. Comp. Neurol. $422,363-379$.

Goodson, J.L., Bass, A.H., 2001. Social behavior functions and related anatomical characteristics of vasotocin/vasopressin systems in vertebrates. Brain Res. Rev. 35, 246-265.

Grober, M.S., George, A.A., Watkins, K.K., Carneiro, L.A., Oliveira, R.F., 2002. Forebrain AVT and courtship in a fish with male alternative reproductive tactics. Brain Res. Bull. 57, 423-425.

Guibbolini, M.E., Avella, M., 2003. Neurohypophysial hormone regulation of $\mathrm{Cl}$ - secretion: physiological evidence for V1-type receptors in sea bass gill respiratory cells in culture. J. Endocrinol. 176, 111-119.

Hofmann, H.A., Fernald, R.D., 2000. Social status controls somatostatin neuron size and growth. J. Neurosci. 20, 4740-4744.

Hyodo, S., Urano, A., 1991. Changes in expression of provasotocin and proisotocin genes during adaptation to hyper- and hypo-osmotic environments in rainbow trout. J. Comp. Physiol., B 161, 549-556.

Hyodo, S., Tsukada, T., Takei, Y., 2004. Neurohypophysial hormones of dogfish, Triakis scyllium: structures and salinity-dependent secretion. Gen. Comp. Endocrinol. 138, 97-104.

Insel, T.R., Young, L.J., 2000. Neuropeptides and the evolution of social behavior. Curr. Opin. Neurobiol. 10, 784-789.

Keverne, E.B., Curley, J.P., 2004. Vasopressin, oxytocin, and social behavior. Curr. Opin. Neurobiol. 14, 777-783.

Kodric-Brown, A., 1978. Establishment and defense of breeding territories in a pupfish (Cyprinodontidae: Cyprinodon). Anim. Behav. 26, 818-834.

Kodric-Brown, A., 1981. Variable breeding systems in pupfish (genus: Cyprinodon): adaptations to changing environments. In: Naiman, R.A., Soltz, D.L. (Eds.), Fishes in North American Deserts. John Wiley and Sons, New York, pp. 205-235.

Kulczykowska, E., 1997. Response of circulating arginine vasotocin and 
isotocin to rapid osmotic challenge in rainbow trout. Comp. Biochem. Physiol., Part A: Mol. Integr. Physiol. 118, 773-778.

Kulczykowska, E., 2001. Responses of circulating arginine vasotocin, isotocin, and melatonin to osmotic and disturbance stress in rainbow trout (Oncorhynchus mykiss). Fish Physiol. Biochem. 24, 201-206.

Larson, E.T., O'Malley, D.M., Melloni Jr., R.H., 2006. Aggression and vasotocin are associated with dominant-subordinate relationships in zebrafish. Behav. Brain Res. 167, 94-102.

Lema, S.C., Nevitt, G.A., 2004a. Variation in vasotocin immunoreactivity in the brain of recently isolated populations of a Death Valley pupfish, Cyprinodon nevadensis. Gen. Comp. Endocrinol. 135, 300-309.

Lema, S.C., Nevitt, G.A., 2004b. Exogenous vasotocin alters aggression during agonistic exchanges in male Amargosa River pupfish (Cyprinodon nevadensis amargosae). Horm. Behav. 46, 628-637.

Lema, S.C., Hodges, M.J., Marchetti, M.P., Nevitt, G.A., 2005. Proliferation zones in the salmon telencephalon and evidence for environmental influence on proliferation rate. Comp. Biochem. Physiol., Part A: Mol. Integr. Physiol. 141, 327-335.

Mahlmann, S., Meyerhof, W., Hausmann, H., Heierhorst, J., Schönrock, C., Zwiers, H., Lederis, K., Richter, D., 1994. Structure, function, and phylogeny of $\left[\mathrm{Arg}^{8}\right]$ vasotocin receptors from teleost fish and toad. Proc. Natl. Acad. Sci. U. S. A. 91, 1342-1345.

Miller, R.R., 1950. Speciation in fishes of the genera Cyprinodon and Empetrichthys, inhabiting the Death Valley region. Evolution 4, 155-163.

Miranda, J.A., Oliveira, R.F., Carneiro, L.A., Santos, R.S., Grober, M.S., 2003. Neurochemical correlates of male polymorphism and alternative reproductive tactics in the Azorean rock-pool blenny, Parablennius parvicornis. Gen. Comp. Endocrinol. 132, 183-189.

Moons, L., Cambré, M., Batten, T.F.C., Vandesande, F., 1989. Autoradiographic localization of binding sites for vasotocin in the brain and pituitary of the sea bass (Dicentrarchus labrax). Neurosci. Lett. 100, 11-16.

Moore, F.L., Richardson, C., Lowry, C.A., 2000. Sexual dimorphism in numbers of vasotocin-immunoreactive neurons in brain areas associated with reproductive behaviors in the roughskin newt. Gen. Comp. Endocrinol. 117, 281-298.

Nürnberger, F., Korf, H.-W., Ali, M., Noakes, D.L.G., 1996. Salinity and vasotocin immunoreactivity in the brain of Rivulus marmoratus (teleostei) Naturwissenschaften 83, 326-328.

Parhar, I.S., Tosaki, H., Sakuma, Y., Kobayashi, M., 2001. Sex differences in the brain of goldfish: gonadotropin-releasing hormone and vasotocinergic neurons. Neuroscience 104, 1099-1110.
Peter, R.E., Macey, M.J., Gill, V.E., 1975. A stereotaxic atlas and technique for forebrain nuclei of the killifish, Fundulus heteroclitus. J. Comp. Neurol. $159,103-128$.

Saito, D., Komatsuda, M., Urano, A., 2004. Functional organization of preoptic vasotocin and isotocin neurons in the brain of rainbow trout: central and neurohypophysial projections of single neurons. Neuroscience 124, 973-984.

Salek, S.J., Sullivan, C.V., Godwin, J., 2002. Arginine vasotocin effects on courtship behavior in male white perch (Morone americana). Behav. Brain Res. 133, 177-183.

Semsar, K., Godwin, J., 2003. Social influences on the arginine vasotocin system are independent of gonads in a sex-changing fish. J. Neurosci. 23, 4386-4393.

Semsar, K., Kandel, F.L.M., Godwin, J., 2001. Manipulations of the AVT system shift social status and related courtship and aggressive behavior in the bluehead wrasse. Horm. Behav. 40, 21-31.

Soltz, D.L., 1974. Variation in life history and social organization of some populations of Nevada pupfish, Cyprinodon nevadensis. Ph.D. thesis, University of California, Los Angeles.

Soltz, D.L., Hirshfield, M.F., 1981. Genetic differentiation of pupfishes (genus Cyprinodon) in the American southwest. In: Naiman, R.J., Soltz, D.L. (Eds.), Fishes in North American Deserts. John Wiley and Sons, New York, pp. 291-333.

Soltz, D.L., Naiman, R.A., 1978. The natural history of native fishes in the Death Valley system. Natural History Museum of Los Angeles County. Sci. Ser. 30, 1-76.

Thompson, R.R., Walton, J.C., 2004. Peptide effects on social behavior: effects of vasotocin and isotocin on social approach behavior in male goldfish (Carassius auratus). Behav. Neurosci. 118, 620-626.

van Praag, H., Kempermann, G., Gage, F.H., 2000. Neural consequences of environmental enrichment. Nat. Rev., Neurosci. 1, 191-198.

Warne, J., 2002. The role of arginine vasotocin in teleost fish osmoregulation. In: Hazon, N., Fink, G. (Eds.), Osmoregulation and Drinking in Vertebrates BIOS Scientific Publishers, Ltd., Oxford, UK, pp. 83-95.

Warne, J.M., Harding, K.E., Balment, R.J., 2002. Neurohypophysial hormones and renal function in fish and mammals. Comp. Biochem. Physiol., Part B Biochem. Mol. Biol. 132, 231-237.

Watters, J.V., Lema, S.C., Nevitt, G.A., 2003. Phenotype management: a new approach to habitat restoration. Biol. Conserv. 112, 435-445.

West-Eberhard, M.J., 2005. Developmental plasticity and the origin of species differences. Proc. Natl. Acad. Sci. U. S. A. 102, 6543-6549. 